\title{
MANAGEMENT OF LATERAL PERIODONTAL CYST EMBEDDED IN BONE
}

\author{
Ahmad H. Almehmadi *
}

\begin{abstract}
Lateral periodontal cysts (LPCs) are odontogenic cysts with rare occurrence and developmental origin. A 46-year old female patient, chronic smoker with non-contributory medical history presented with dull pain/pressure in the left mandibular premolar region and the associated teeth were vital on pulp testing. Periapical radiograph revealed a well- circumscribed, radiolucent region measuring $<1 \mathrm{~cm}$ in diameter with loss of lamina dura in teeth, which were in contact with the lesion, and interproximal buccal bone loss. The clinical and radiographic features were suggestive of LPC and the patient was advised to undergo conservative surgical management of the cystic lesion. The full-thickness mucoperiosteal flap was elevated, complete debridement was done, and enucleation was performed using a surgical curette. The flaps were approximated and then sutured. Histological examination was performed on the tissue sample obtained during surgery and the findings confirmed the diagnosis of LPC. The post-operative follow-up was uneventful with no biological complications such as pain, swelling, or bleeding at the surgical site and periodontal healing was satisfactory.
\end{abstract}

KEYWORDS: Lateral periodontal cyst; Enucleation; Curettage; Histology

\section{INTRODUCTION}

Lateral periodontal cysts (LPC) belong to the class of odontogenic developmental cysts and it is a non-inflammatory cyst that occurs on the lateral surface of a vital tooth root. ${ }^{[1,2]}$ The predilection of these cysts is at the level of mandibular premolars, but they have also been observed to occur in other regions. ${ }^{[3]}$ They constitute $0.4 \%$ of odontogenic cysts and $0.7 \%$ of all the cysts occurring in the jaw bones. ${ }^{[4]}$ The LPC are thought to have been developed from either the epithelial cell rests of Malassez, reduced enamel epithelium, or remnants of dental lamina, but the etiology still remains unclear. ${ }^{[5]}$

These cysts are usually asymptomatic and they are diagnosed during routine clinical or radiographic examination. Radiographs of the cyst show wellcircumscribed round or ovoid radiolucent lesions that have sclerotic margins and they are usually under $1 \mathrm{~cm}$ in diameter. The existing literature states that there is no racial predilection for these

\footnotetext{
* Department of Oral Biology, Faculty of Dentistry, King Abdulaziz University, Jeddah, Saudi Arabia
} 
cysts and contrasting results show either a male preponderance or equal sex distribution. ${ }^{[6-9]}$ The prevalence of LPCs were the highest in the fifth and sixth decades of life and frequently occur in the mandible, typically on the lateral aspect of root surfaces in the canine-premolar region. ${ }^{[10-11]}$

On histological examination, the LPCs present with thin, non-keratinized epithelium that are 1-5 cell layers in thickness and it mimics the reduced enamel epithelium. ${ }^{[12]}$ It is composed of a cystic cavity with a connective tissue wall and is devoid of inflammatory component. The focal thickenings of epithelium, also called as plaques have been observed to contain clear epithelial cells with glycogen content. The subjacent connective tissue wall shows a degree of hyalization (6). These cysts share a common histogenesis with two cysts, namely gingival cyst of the adult (GCA) and botyroid odontogenic cyst (BOC). The LPCs are considered to be the intraosseous counterpart to the extraosseous GCA and the BOCs are treated as a rare multilocular variant of the LPCs. ${ }^{[13]}$ The differential diagnosis to these cysts can be any of the above-mentioned cysts, odontogenic keratocyst, or lateral radicular cyst. ${ }^{[1]}$

The untreated lesions can result in bony expansion, clinical symptoms, displacement of tooth, perforation of the cortical bone, or resorption of the tooth root. ${ }^{[10]}$ The treatment of LPCs employs conservative surgical management that includes enucleation and curettage. There are various reports in the current literature that employ guided tissue regeneration, bone grafts, or various regenerative modalities for the treatment of LPCs. ${ }^{[14-15]}$ A systematic review conducted by Chrcanovic included 146 studies and it concluded that conservative surgical treatment with appropriate follow-up was sufficient for the management of LPC ${ }^{[10]}$ This case report demonstrates the classic conservative surgical approach (enucleation+curettage) utilised for LPC embedded in the mandibular premolar region.

\section{CASE REPORT}

A 46-year old female patient reported to the clinic with the chief complaint of dull pain or pressure sensation in the left mandibular premolar region (\#34-\#35). The pain was intermittent and the patient did not present with any contributory medical history. The anamnesis revealed that the patient was a chronic smoker who smoked 1 pack per day for the past 10 years. The patient did not consume any medication that may have affected the periodontal tissue metabolism. The clinical examination revealed there was mild gingival redness in the mandibular premolar region, but the periodontal parameters were within normal limits and vitality tests showed that \#34 and \#35 had vital pulps [Figure 1 (Pre-op)]. Periapical radiograph revealed well-circumscribed, unilocular, radiolucent region measuring about $1 \mathrm{~cm}$ in diameter near the roots of mandibular \#34\#35 region [Figure 2 (IOPA-34,35)].A preliminary diagnosis of LPC was made based on clinical and radiographic findings, and informed consent was obtained from the patient for the surgical treatment modality. Scaling and root planing was performed prior to the surgical procedure. Adequate local anesthesia was obtained with the infiltration of $2 \%$ lidocaine with 1:100,000 epinephrine from mandibular left canine to first molar region. A trapezoidal full thickness mucoperiosteal flap was

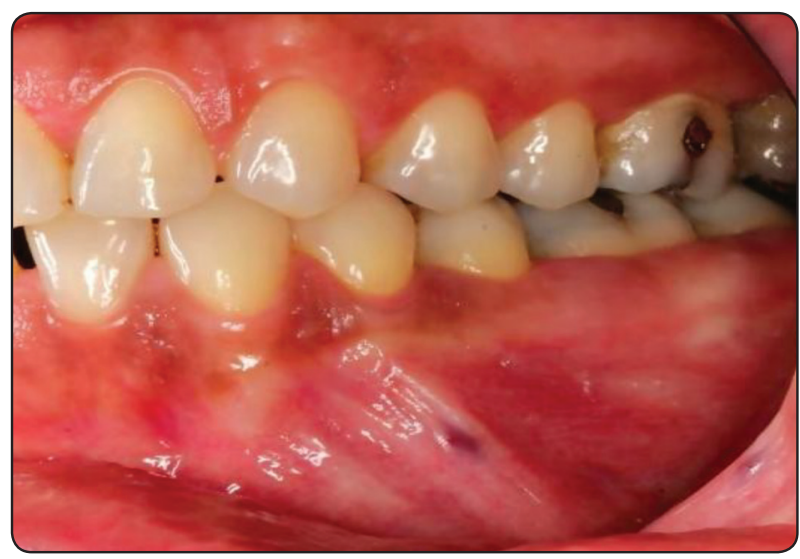

Fig. (1) Pre-operative intraoral picture. Note tissues look normal with no swelling nor inflammation. 
raised from \#33-\#36 region, the cyst embedded in bone was visualized. A window was created to access the cyst buccally and a small diamond bur (Heisinger ${ }^{\circledR}$ \#008) on high speed was employed. The size of the window $(1 \mathrm{~cm} \times 1 \mathrm{~cm})$ was approximated from the location of cyst and its measurements on the radiographs and the cyst capsule was detached from the adjacent bone [Figure 3 (flap reflection and window creation to expose cyst)]. The enucleation of the cyst was performed using a surgical curette and the granulation tissue was removed, the cyst measured $(1 \mathrm{cmX} 1 \mathrm{~cm})$ [Figure 4 (Enucleation of the cyst)]. Following complete debridement, the bony cavity was visualized extending from the buccal aspect [Figure 5A (bony cavity)]. The flaps were approximated and sutured using synthetic, resorbable, vicryl sutures (Ethicon Inc, Ohio, USA), [Figure 5B (suture placement)] and postoperative instruction included prescription of antibiotics (Amoxicillin 500mg (bid for 5 days) and analgesics (Paracetamol 650mg tid for 4 days). The tissue sample was sent for histological examination. During the post-operative follow-up at 1 week, clinical healing was achieved without any biological complications such as pain, hemorrhage, or swelling [Figure 6 (surgery follow up)].

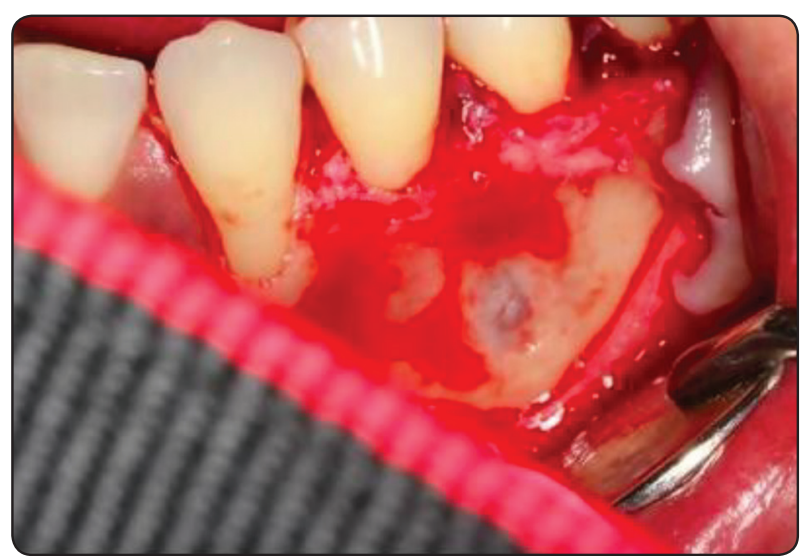

Fig. (3) Flap reflection and window creation. The cyst was completely embedded in bone and a window creation to expose the cyst was necessary by the use of surgical round bur.

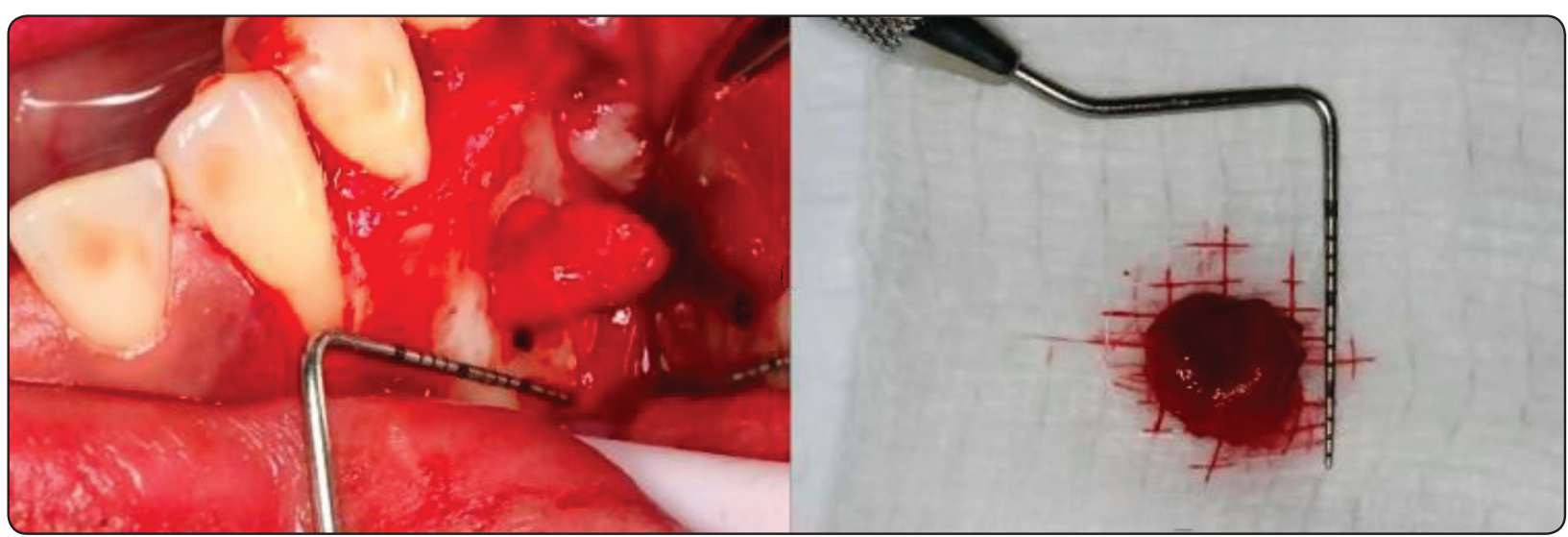

Fig. (4) Enucleation of the cyst. Note the cyst is measured $1 \mathrm{cmX} 1 \mathrm{~cm}$ and was removed with surgical curette. 


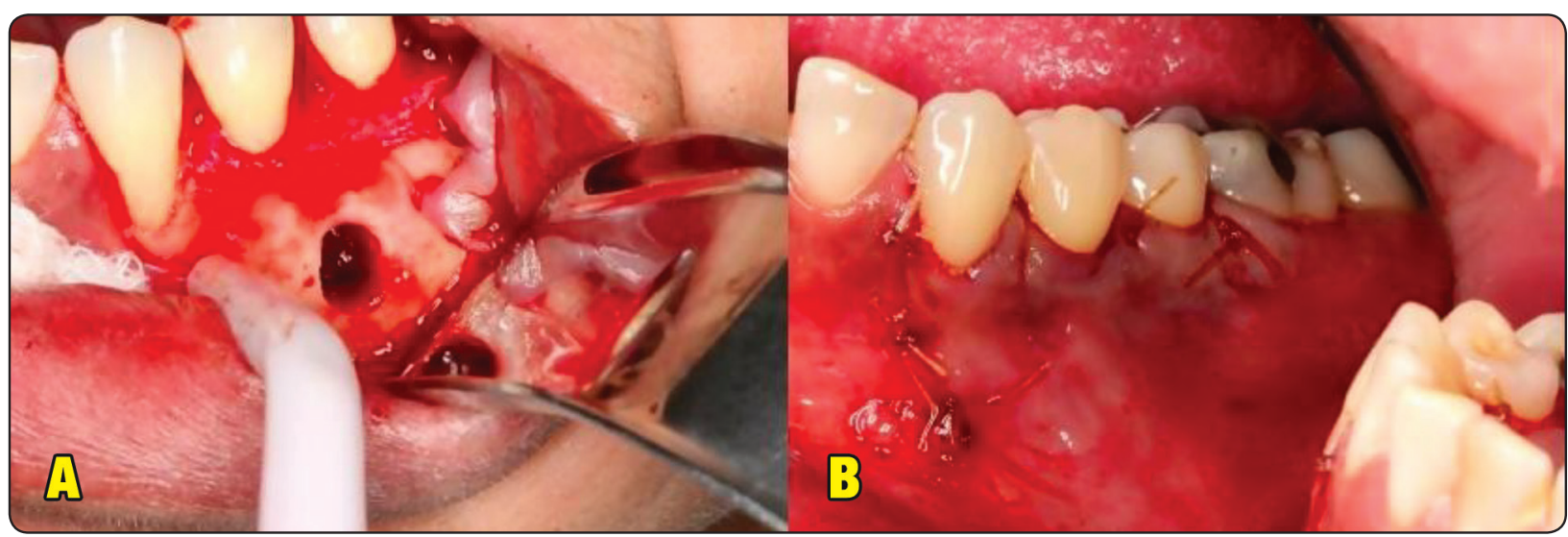

Fig. (5) Bony walls of the cyst cleaning and suturing. A. The cyst bony walls were inspected and cleaned with saline. B. Approximation of the flap and suturing of the wound performed.

The tissue sample was fixed in $10 \%$ formaldehyde solution and stained using hematoxylin- eosin dyes. Under microscopic observation, it was observed that there was vascular granulomatous region overlying with squamous epithelium and epithelial cells rich in glycogen content were observed. A zone of hyalinization was observed in the connective tissue capsule. There were no inflammatory cells in the connective tissue [Figure 7 (Histology)]. The clinical, radiographic, and histological examination was consistent with the diagnosis of LPC.

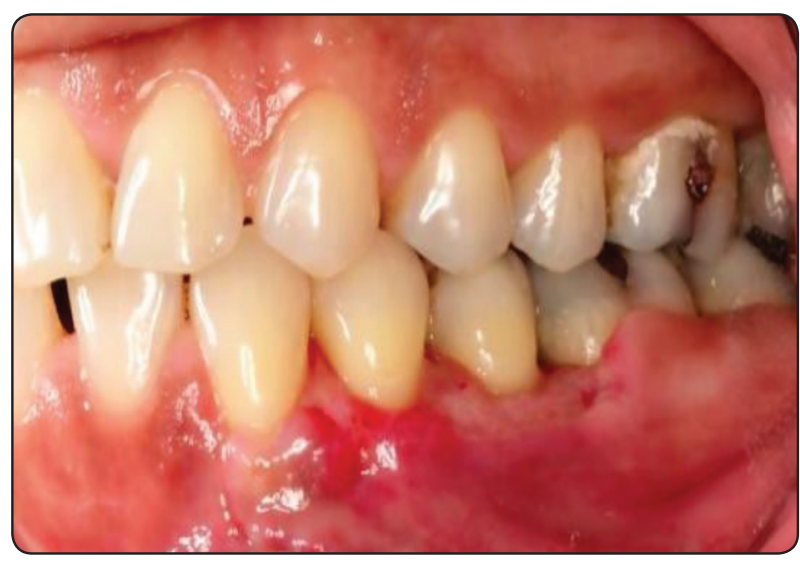

Fig. (6) Follow up of the surgery. Note surgery went uneventful and patient is healing normally.

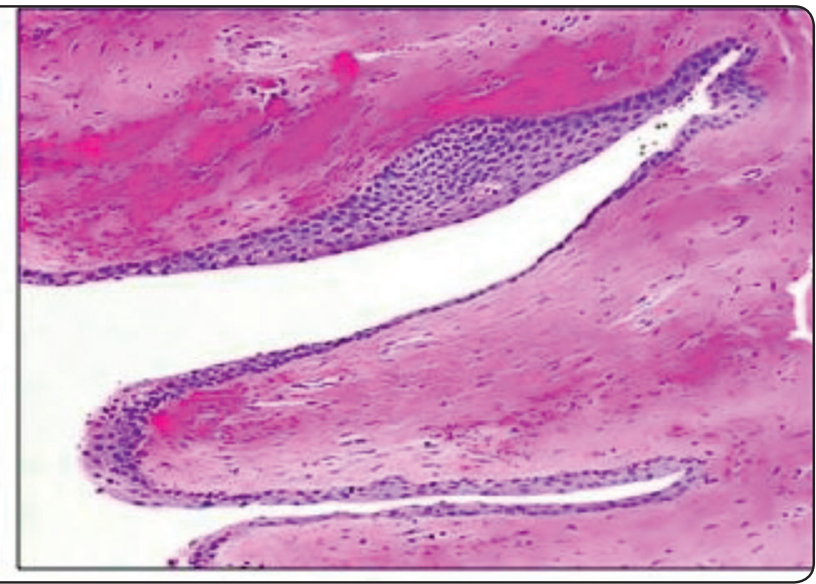




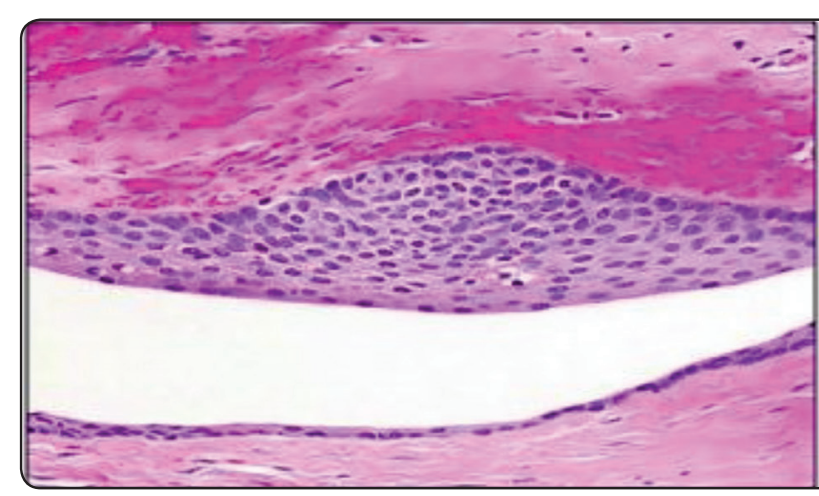

\section{DISCUSSION}

LPCs are developmental, non-inflammatory, odontogenic cysts that are intraosseous in nature and presents with a rare occurrence in the oral cavity. The preferred treatment for LPC is Partsch cystectomy which is the enucleation of the cyst followed by primary closure and leaving the bone fill to occur. ${ }^{[16]}$ The diagnosis is primarily made from the radiographic feature and clinical presentation because patients with LPC do not present with any symptoms. In the present case, the clinical examination did not reveal any significant findings, whereas, the radiograph showed a well-demarcated, radiolucent lesion with corticated borders distinctive of LPC. The teeth subjacent to the cyst were vital and did not require any form of endodontic therapy. There was no associated mobility of teeth reported in this case.

Histological examination revealed squamous epithelial layer of variable thickness around a cystic cavity with non-inflammatory connective tissue wall. $^{[12,17]}$ In this case, similar findings were observed under microscopic examination and the epithelial cells containing glycogen content were observed. The connective tissue capsule did not show any signs of inflammation and they usually present with mature collagenous fibrous tissue. ${ }^{[18-20]}$ In this case, a zone of hyalinization was also observed in the connective tissue capsular region. Some histological features are shared with other cysts such as GCA and BOC, but subtle differences exist and LPCs generally have low recurrence rates. ${ }^{[21]}$
Fig. (7) Histological findings. Note thin epithelial layer covering the granulomatous connective tissue with some areas of focal thickening which is a characteristic of lateral periodontal cyst. No inflammatory cells were detected in the connective tissue.

Meltzer et al reported the treatment of a 73-yearold-man diagnosed with LPC without the use of guided tissue regeneration or bone grafts, and reported the defect fill with complete regeneration of bone at 1 year follow-up. ${ }^{[22]} \mathrm{A}$ similar result was observed by Angelopoulou

and Angelopoulos et al in the case report on mandibular LPC enucleation, where there was bone fill after 1 year when assessed using periapical radiographs. ${ }^{[12]}$ In this case, the barrier techniques, bone grafts, or regenerative modalities were not employed and the classic conservative surgical approach was followed for the management of LPC. At 1-week follow- up, there were no biological complications like pain, swelling, or hemorrhage at the surgical site. A systematic review conducted on the treatment of odontogenic cysts concluded that enucleation of LPC would suffice in the management of the lesion. ${ }^{[10]}$ Future research directed at employing cone beam computed tomography for radiographic assessment with longer recall periods are warranted.

\section{CONCLUSION}

This case report demonstrated the conservative surgical management of LPC embedded in bone employing enucleation and curettage of the lesion at the site of left mandibular premolar region. The cyst measured approximately $1 \mathrm{~cm}$ in diameter and the post-operative follow-up showed that there were no biological complications associated with the treatment procedure. 


\section{FINANCIAL SUPPORT}

Nil

\section{CONFLICTS OF INTEREST}

There are no conflicts of interest.

\section{REFERENCES}

1. Kramer I, Pindborg J, Shear M. WHO Histological Typing of Odontogenic Tumours. In: 2nd Ed. Geneva: SpringerVerlag; 1992.p. 34-118.

2. Banes L, Eveson J, Reichart P, Sidransky D. World Health Organization Classification of tumors: Pathology and Genetics of Head and Neck Tumors. Lyon: IARC Press. 2005;

3. Krier PW. Lateral periodontal cyst. Oral Surg Oral Med Oral Pathol. 1980 May;49(5):475.

4. Shear M, Speight P. Cysts of the Oral and Maxillofacial Regions. In Blackwell: Oxford; 2007.

5. Demirkol M, Ege B, Yanik S, Aras MH, Ay S. Clinicopathological study of jaw cysts in southeast region of Turkey. Eur J Dent. 2014 Jan;8(1):107-11.

6. Altini M, Shear M. The lateral periodontal cyst: an update J Oral Pathol Med Off Publ Int Assoc Oral Pathol Am Acad Oral Pathol. 1992 Jul;21(6):245-50.

7. Ortega A, Fariña V, Gallardo A, Espinoza I, Acosta S. Nonendodontic periapical lesions: a retrospective study in Chile. Int Endod J. 2007 May;40(5):386-90.

8. Kelsey WP, Kalmar JR, Tatakis DN. Gingival cyst of the adult: regenerative therapy of associated root exposure. A case report and literature review. J Periodontol. 2009 Dec;80(12):2073-81.

9. Nikitakis NG, Brooks JK, Melakopoulos I, Younis RH, Scheper MA, Pitts MA, et al. Lateral periodontal cysts arising in periapical sites: a report of two cases. J Endod. 2010 Oct;36(10):1707-11.

10. Chrcanovic BR, Gomez RS. Gingival cyst of the adult, lateral periodontal cyst, and botryoid odontogenic cyst: An updated systematic review. Oral Dis. 2019 Jan; 25(1): 26-33.

11. Soares de Lima A, Naval Machado M, Braga A, De Souza
M. Lateral periodontal cyst: Aetiology, diagnosis and clinical significance. A review and report of case. Rev de Clín Pesqui Odontol. 2005;1:55-9.

12. Angelopoulou E, Angelopoulos AP. Lateral periodontal cyst. Review of the literature and report of a case. J Periodontol. $1990 \mathrm{Feb}$;61(2):126-31.

13. El-Naggar A, Chan J, Grandis J, Takata T, Slootweg P. World Health Organization Classification of tumors: Pathology and Genetics of Head and Neck Tumors. IARC Press: Lyon. 2017;

14. Sivolella S, Perin C, Capecchi M, Buongiorno V, Valente M. Guided Bone Regeneration in the Treatment of a Lateral Periodontal Cyst: 2-Year Clinical and Radiologic Follow-up. Int J Periodontics Restorative Dent. 2018 Oct;38(5):747-754.

15. Meseli SE, Agrali OB, Peker O, Kuru L. Treatment of lateral periodontal cyst with guided tissue regeneration. Eur J Dent. 2014 Jul;8(3):419-23.

16. Partsch C. Zur behandlung der kieferzysten. Dtsch Mschr Zahnheilkd. 1910;28:252.

17. Cohen DA, Neville BW, Damm DD, White DK. The lateral periodontal cyst. A report of 37 cases. J Periodontol. 1984 Apr;55(4):230-4.

18. Wysocki GP, Brannon RB, Gardner DG, Sapp P. Histogenesis of the lateral periodontal cyst and the gingival cyst of the adult. Oral Surg Oral Med Oral Pathol. 1980 Oct;50(4):327-34.

19. Rasmusson LG, Magnusson BC, Borrman H. The lateral periodontal cyst. A histopathological and radiographic study of 32 cases. Br J Oral Maxillofac Surg. 1991 Feb;29(1):54-7.

20. Eliasson S, Isacsson G, Köndell PA. Lateral periodontal cysts. Clinical, radiographical and histopathological findings. Int J Oral Maxillofac Surg. 1989 Aug;18(4):191-3.

21. Moskow BS, Siegel K, Zegarelli EV, Kutscher AH, Rothenberg F. Gingival and lateral periodontal cysts. J Periodontol. 1970 May;41(5):249-60.

22. Meltzer JA. Lateral periodontal cyst: report of a case with 1-year reentry. Int J Periodontics Restorative Dent. 1999 Jun;19(3):299-303 